Trinity University

Digital Commons @ Trinity

$2-2021$

\title{
Culturable Root Endophyte Communities are Shaped by Both Warming and Plant Host Identity in the Rocky Mountains, USA
}

Kelly G. Lyons

Trinity University, klyons@trinity.edu

M. Mann

Molly Lenihan

Trinity University, mlenihan@trinity.edu

Olivia Roybal

Trinity University, oroybal@trinity.edu

Kelly Carroll

Trinity University, kcarroll@trinity.edu

See next page for additional authors

Follow this and additional works at: https://digitalcommons.trinity.edu/bio_faculty

Part of the Biology Commons

\section{Repository Citation}

Lyons, K. G., Mann, M., Lenihan, M., Roybal, O., Carroll, K., Reynoso, K., Kivlin, S. N., ... \& Rudgers, J. A. (2021). Culturable root endophyte communities are shaped by both warming and plant host identity in the Rocky Mountains, USA. Fungal Ecology, 49, Article 101002. http://doi.org/10.1016/j.funeco.2020.101002

This Article is brought to you for free and open access by the Biology Department at Digital Commons @ Trinity. It has been accepted for inclusion in Biology Faculty Research by an authorized administrator of Digital Commons @ Trinity. For more information, please contact jcostanz@trinity.edu. 


\section{Authors}

Kelly G. Lyons, M. Mann, Molly Lenihan, Olivia Roybal, Kelly Carroll, Kyle Reynoso, S. N. Kivlin, D. L. Taylor, and J. A. Rudgers 


\title{
Culturable root endophyte communities are shaped by both warming and plant host identity in the Rocky Mountains, USA
}

\author{
Kelly G. Lyons a, c, *, Michael Mann ${ }^{\text {b, c }}$, Molly Lenihan a , Olivia Roybal a , Kelly Carroll a , \\ Kyle Reynoso ${ }^{\text {a }}$, Stephanie N. Kivlin ${ }^{\text {b, c, d }}$, D. Lee Taylor ${ }^{\text {b }}$, Jennifer A. Rudgers b, c \\ a Dept of Biology, Trinity University, San Antonio, TX, 78212, USA \\ ${ }^{\mathrm{b}}$ Dept of Biology, University of New Mexico, Albuquerque, NM, 87131, USA \\ c The Rocky Mountain Biological Laboratory, Gothic, CO, 81224, USA \\ d Dept of Ecology and Evolutionary Biology, University of Tennessee, Knoxville, TN, 37996, USA
}

\section{A R T I C L E I N F O}

\section{Article history:}

Received 21 November 2019

Received in revised form

4 August 2020

Accepted 18 September 2020

Available online 11 November 2020

Corresponding Editor: James White III

\section{Keywords:}

Alpine

Climate change

Community composition

Fungi

Grassland

Meadow

Mutualism

Symbiosis

\begin{abstract}
A B S T R A C T
Understanding the biogeographic patterns of root-associated fungi and their sensitivity to temperature may improve predictions of future changes in terrestrial biodiversity and associated ecosystem processes, but data are currently limited. Anticipating change will require combining observational data, which predict how climatic factors limit current species distributions, with direct manipulations of climate, which can isolate responses to specific climate variables. Root endophytes are common symbionts of plants, particularly in arctic and alpine environments, yet their responses to climate warming are not resolved. Here, we directly cultured endophytic fungi from roots collected along altitudinal gradients in replicated mountain watersheds and from a $27 \mathrm{y}$ field warming experiment in the Rocky Mountains, USA, to improve understanding of climate impacts on fungal root endophytes. Fungal taxa that were common at high elevations declined most under climate warming, whereas low elevation dominants responded neutrally or increased with experimental warming. Altitudinal gradients in fungal communities were strongly specific to the plant host species. Specifically, Poa species had 25-60\% greater fungal isolate abundance and 25-38\% greater fungal diversity at high elevations than at low elevation sites. In contrast, Festuca thurberi had 64\% lower fungal diversity on roots at high elevation than at low elevation. Our results help to improve understanding of the potential for climate change to alter plant-fungal interactions in mountain ecosystems.
\end{abstract}

(c) 2020 Elsevier Ltd and British Mycological Society. All rights reserved.

\section{Introduction}

Under the business-as-usual scenarios, climate models predict a $2-4{ }^{\circ} \mathrm{C}$ increase in global mean annual temperature over the next century (IPCC, 2014; Masson-Delmotte et al., 2018) with intensified warming at high elevations (Rangwala and Miller, 2012; Wang et al., 2016). Many species experience shifts in their geographic distributions as a consequence of contemporary climate change (Parmesan, 2006; Chen et al., 2011). In particular, many plant species are moving up mountainsides into cooler, higher elevation climates (Lenoir et al., 2008; Engler et al., 2011). The ability to anticipate future range shifts will require a combination of observational data, to predict how climatic factors limit current species distributions, and

\footnotetext{
* Corresponding author. Dept of Biology, Trinity University, San Antonio, TX, USA. E-mail address: klyons@trinity.edu (K.G. Lyons).
}

direct manipulations of climate, to isolate response mechanisms to specific climate variables (Knapp et al., 2018; Urban, 2019).

For plants and animals, observational and experimental data on the effects of climate change on species distributions and community structure are becoming widely available (e.g., Diamond et al., 2012; Liu et al., 2018), but such data remain limited for fungi and other microorganisms (Miyamoto et al., 2018; Kazenel et al., 2019). Understanding the biogeographic patterns of root-associated fungi and their sensitivity to temperature may improve predictions of future changes in terrestrial biodiversity and associated ecosystem function under climate warming. Root endophytes are common symbionts of plants, particularly in arctic and alpine environments (Haselwandter and Read, 1980; Porras-Alfaro and Bayman, 2011). These fungi can have important ecological functions by improving plant nutrient uptake (Newsham, 2011) and buffering plants under warming or drought (Kivlin et al., 2013). The abundance, diversity, and species composition of plant-associated fungi often follow 
altitudinal patterns (reviewed by Kivlin et al., 2017), suggesting that fungi are sensitive to temperature in mountain ecosystems. For example, both root colonization by arbuscular mycorrhizal fungi (AMF) and the diversity of AMF declined with elevation (Gardes and Dahlberg, 1996; Wu et al., 2007; Gai et al., 2012), although exceptions to these patterns also exist (Ruotsalainen et al., 2004; Zubek et al., 2009). Despite their putative importance in plants, altitudinal patterns in the composition and colonization of nonmycorrhizal root-associated fungi are poorly resolved (Read and Haselwandter, 1981; Schmidt et al., 2008), representing just 31 of 374 records in our meta-analysis of altitudinal patterns in fungal symbiosis in plants (Kivlin et al., 2017). This lack of information limits our ability to predict how these fungi, and their host plants, may respond to climate change.

Traditionally, abiotic determinants of species distributions, such as climate, are assumed to operate over broad spatial scales, while biotic interactions, such as those among plants and fungi, are expected to have the strongest influence at local scales (Bowman et al., 2017). However, accumulating evidence suggests that biotic interactions can be important broad-scale determinants of species distributions (Thuiller et al., 2008; Van der Putten et al., 2010; Lewis et al., 2017; Lynn et al., 2019). Indeed, several examples for root-associated fungi suggest an overriding influence of host plant identity on fungal composition, abundance, or diversity (Davison et al., 2016; Põlme et al., 2018; Ramirez et al., 2019). Host plants may affect the distributions of root endophytes if variation in plant species traits such as root architecture (Maherali, 2014) or chemical quality and stoichiometry (Averill et al., 2019) are correlated with fungal communities.

In this study, we assessed the abundance, diversity, and composition of culturable root endophytes in replicated pairs of high and low elevation sites and in a $27 \mathrm{y}$ warming experiment in the Rocky Mountains, USA. Plant species in this region have moved, on average, $40 \mathrm{~m}$ higher in elevation during the past $65 \mathrm{y}$ (Zorio et al., 2016). Likewise, plant species composition has responded to experimental warming. For instance, an increase of $2{ }^{\circ} \mathrm{C}$ during $25 \mathrm{y}$ of year-round infrared heating increased sedges, decreased grass abundance, and increased AMF and root endophyte colonization for some grass species (Rudgers et al., 2014). Here, we focused on fungi that are culturable (i.e., non-obligate symbionts) because they can be isolated, stored, and manipulated. These taxa have potential to play roles in land management and restoration, improving practices such as assisted migration or myco-remediation. We used a combination of culturing and Sanger sequencing to assess whether: (1) altitude acts as a determinant of abundance, diversity, and composition of culturable root endophytic fungi; and (2) culturable root fungi respond to experimental warming. By combining observational and experimental datasets, we then evaluated whether (3) fungal responses to direct warming are predictable from their altitudinal distributions within a mountain ecosystem.

\section{Materials and methods}

\subsection{Focal host plant species}

We selected four pairs of congeneric grass species, plus an additional species Trisetum spicatum, that lacked a congener but is abundant over a broad altitudinal range (Table 1 ). Within congeneric pairs, one species had a broad altitudinal distribution and the other was restricted to low elevations (Lynn et al., 2019).

\section{2. altitudinal survey}

We collected plants within three replicate watersheds (Slate River, Washington Gulch, and East River) in the Gunnison National Forest near the Rocky Mountain Biological Laboratory (RMBL),
Table 1

List of focal plant species for the Altitudinal Gradients Survey at high elevation $(\mathrm{H})$ or low elevation (L) sites and in the Warming Meadow Experiment (W). Plant species are grouped by Tribe/Subtribe within the Poaceae, then alphabetically by genus. Distribution indicates the typical altitudinal range of each species in the Upper Gunnison Basin based on plant surveys (Lynn et al., 2019).

\begin{tabular}{llll}
\hline Tribe-Subtribe & Distribution & Plant Species & Collection \\
\hline Stipeae & broad & Achnatherum lettermanii & $\mathrm{H} / \mathrm{L} / \mathrm{W}$ \\
Stipeae & low & Achnatherum nelsonii & $\mathrm{L}$ \\
Triticeae & broad & Elymus trachycaulus & $\mathrm{H} / \mathrm{L}$ \\
Triticeae & low & Elymus elymoides & $\mathrm{L}$ \\
Poeae-Loliinae & broad & Festuca thurberi & $\mathrm{H} / \mathrm{L} / \mathrm{W}$ \\
Poeae-Lollinae & low & Festuca saximontana & $\mathrm{L}$ \\
Poeae-Poinae & broad & Poa leptocoma & $\mathrm{H} / \mathrm{L}$ \\
Poeae-Poinae & low-mid & Poa pratensis & $\mathrm{H} / \mathrm{L} / \mathrm{W}$ \\
Aveneae & broad & Trisetum spicatum & $\mathrm{H} / \mathrm{L}$ \\
\hline
\end{tabular}

Gunnison County, Colorado, USA. Each watershed had a high and a low elevation subalpine meadow site (Table 2, Supporting Material Fig. S1). Sites were chosen based on the presence of the focal grass species at low ( 2800-3000 m) or high ( $3200-3400 \mathrm{~m})$ elevation.

\section{3. warming meadow experiment}

The warming experiment was established across a small glacial moraine spanning $10 \mathrm{~m}$ along an east-west oriented gradient (38.95136240 N, -106.98635923 W, elevation 2885 m, Supporting Material Fig. S1) (Harte and Shaw, 1995; Price and Waser, 2000), with 1-2 $\mathrm{m}$ change in elevation along the moraine. Approximately 60 herbaceous perennials and a few annuals have been identified in the plots (Price and Waser, 2000; De Valpine and Harte, 2001). The higher and drier, western portion of the moraine was dominated by sagebrush (Artemisia tridentata), rabbitbrush (Ericameria parryi), and bunchgrasses (Festuca thurberi and Achnatherum spp.) while the wetter, eastern portion was dominated by willow (Salix spp.) and monkshood (Aconitum columbianum). We collected root samples from three grass species that were present in both the Altitudinal Survey and the Warming Meadow. These were: A. lettermanii, $P$. pratensis, and $F$. thurberi (Table 1 ).

The warming experiment was designed to simulate conditions under a doubling of atmospheric $\mathrm{CO}_{2}$ (Harte and Shaw, 1995). Along the moraine, ten plots $(10 \times 3 \mathrm{~m})$ alternated between a warmed or control treatment. Each plot was oriented with the long axis of the plot running west to east from higher to lower elevation and drier to wetter soil conditions, respectively. Beginning fall 1990, two electric heaters ( $15 \mathrm{~W} \mathrm{~m}^{-2}$ infrared radiation) were suspended on aircraft cable $\sim 1.5-2.5 \mathrm{~m}$ above the center of the long axis of the warmed plots. Heating began January 6,1991 , and has run continuously until July 2019. A third heater was added between two existing heaters in May 1993, increasing the total flux to $22 \mathrm{~W} \mathrm{~m}^{-2}$. Heaters shaded only $2 \%$ of the soil surface, and there was no experimental control for the presence of heating infrastructure. The treatment warmed the top $15 \mathrm{~cm}$ of soil $\sim 2{ }^{\circ} \mathrm{C}$ on average, decreased soil water content by $10-20 \%$, and extended the duration of snow-free soil conditions at each end of the growing season by $\sim 12$ d (Harte and Shaw, 1995; Saleska et al., 2002; Harte et al., 2015).

Heating had the strongest effects on abiotic conditions, plant communities, and fungal colonization of roots at the upper, drier end of the moraine within each plot. Of particular importance to this study, graminoid (grass and sedge) species composition diverged between warmed and control plots over time (Rudgers et al., 2014). In 2011, sedges occupied a larger percentage of sampled quadrats under warming in the upper and mid-elevation (drier) portions of the plots, while grasses generally declined in these drier areas. At the upper, drier end of the moraine, AMF root colonization increased in one grass 
Table 2

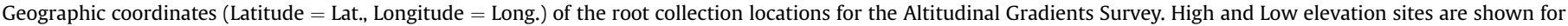
each watershed, the East River, Washington Gulch, and Slate River. Elevation is given in $\mathrm{m}$.

\begin{tabular}{|c|c|c|c|c|c|c|c|c|c|}
\hline & \multicolumn{3}{|l|}{ East River } & \multicolumn{3}{|l|}{ Slate River } & \multicolumn{3}{|c|}{ Washington Gulch } \\
\hline & Lat. & Long. & Elev. & Lat. & Long. & Elev. & Lat. & Long. & Elev. \\
\hline High & 38.97529 & -106.978 & 3358 & 38.97073 & -107.059 & 3210 & 38.97018 & -107.03 & 3381 \\
\hline Low & 38.96642 & -106.99 & 3001 & 38.93282 & -107.05 & 2812 & 38.9346 & -107.011 & 2945 \\
\hline
\end{tabular}

species and in sagebrush, but did not change in sedges. Intraradical non-AMF fungi, characterized by septate hyphae, did not differ between control and warming plots within individual graminoid species. However, due to increases in the abundance of some graminoid species with large colonization by septate fungi, the abundance of septate fungi increased at the plot scale (Rudgers et al., 2014).

\subsection{Sampling methods}

Altitudinal Survey. We sampled grasses between 11 and 17 July 2017 from naturally occurring populations. All species were sampled from low-elevation habitats, while only species with broad distribution were sampled from high-elevation habitats (Table 1). Within a site, six individuals of each species were uprooted using a bleachsterilized soil knife. Care was taken to obtain roots from the base of the plant to the edge of rooting depth. We removed as much soil and litter as possible from the roots and then combined all six individuals per species into a single, sterile Whirl-pak® (Nasco, Fort Atkinson, WI, USA). Whirl-paks were stored on ice and returned to the lab.

Warming Meadow Experiment. We sampled grasses during 12-18 July 2017 from the warming experiment (Table 1). Due to the sensitive nature of the long-term warming experiment, roots from just three individuals per species per plot were collected and with as little disturbance as possible by wedging a bleach-sterilized soil knife under one edge of the plant root system. Since entire plants could not be removed from the plot, we were cautious to collect only live roots that were attached to the base of the plant. We replaced disturbed soil and caused no plant mortality. Roots of each replicate plant were placed into separate sterile Whirl-paks, placed on ice, and returned to the lab.

\subsection{Fungal cultures}

Culturing occurred within $24 \mathrm{~h}$ for all samples. Root samples were cultured under a biological safety cabinet using standard sterile technique. Samples were surface-sterilized by submerging in 95\% ethanol for $1 \mathrm{~min}$, then in $1 \%$ sodium hypochlorite solution for $2 \mathrm{~min}$. Roots were then rinsed three times with sterile, DI water. Root fragments were cut into smaller segments $(\sim 3 \mathrm{~mm})$ using a flamesterilized scalpel, then placed onto $10 \mathrm{~cm}$ diameter Petri plates containing malt extract agar with penicillin and streptomycin $(50 \mathrm{mg} / \mathrm{L})$. Plates were sealed with parafilm then incubated at room temperature. We checked plates daily and transferred unique morphotypes to $50 \mathrm{~mm}$ Petri dishes of the same media to create pure cultures. The last round of sub-culturing for unique morphotypes took place until August 4, 2017 (18 days after the first round of sub-culturing). The original plates were monitored until the end of August, at which point the plates were saturated and no new fungi appeared. We maintained and counted all replicate morphotypes per species per treatment. All isolates were archived in sterile water in replicate reference collections at University of New Mexico and Trinity University.

\subsection{Fungal identification}

DNA extraction and PCR. Multiple subcultures of each unique morphotype were randomly selected for sequencing. We extracted DNA with the Qiagen Dneasy Plant Kit and amplified via PCR with the
ITS1-FL and TW13 primers (White et al., 1990; Taylor et al., 2008). Cultures that contained the $50-500$ bp intron between the ITS1-FL and the ITS1 region were additionally amplified using the ITS1 (White et al., 1990) and TW13 primers. Each PCR used the Phusion High-Fidelity DNA polymerase kit (ThermoFisher Scientific, Waltham, MA). We used $5 \mu \mathrm{L}$ of $5 \mathrm{x}$ High fidelity buffer, $0.5 \mu \mathrm{L}$ of dNTP, $0.25 \mu \mathrm{L}$ of each primer at $25 \mu \mathrm{M}, 18.75$ of nanopore water and $0.25 \mu \mathrm{L}$ of Phusion, and $1 \mu \mathrm{L}$ of template $(\sim 10 \mathrm{ng} / \mu \mathrm{L})$. The thermocycler conditions for the ITS1-FL and TW13 pair consisted of denaturing at $96{ }^{\circ} \mathrm{C}$ for $2 \mathrm{~min}, 27$ cycles of denaturing $94^{\circ} \mathrm{C}$ for $30 \mathrm{~s}$, annealing at $60.6^{\circ} \mathrm{C}$ for $40 \mathrm{~s}$, extending at $72{ }^{\circ} \mathrm{C}$ for $2 \mathrm{~min}$, and a final extension at $72{ }^{\circ} \mathrm{C}$ for $10 \mathrm{~min}$. Thermocycler conditions for the ITS1 and TW13 pair were identical except the annealing temperature was increased to $64{ }^{\circ} \mathrm{C}$ and the number of cycles was increased to 29 cycles. Each amplicon was Sanger sequenced by Genewiz (South Plainfield, NJ).

Bioinformatics. We trimmed the raw sequences to exclude lowquality bases (quality score < 20) and assembled the sequences using 4 peaks (Griekspoor and Groothuis, 2018) and Geneious (2018). The assembled sequences were aligned using MAFFT v7.407 (Katoh and Standley, 2013) and trimmed to include only the ITS region by removing nucleotides beyond the ITS1 and ITS4 primer regions. The sequences were clustered into operational taxon units (OTUs) at $97 \%$ similarity with UCLUST implemented in USEARCH (v10.0.240, 32 bit) (Edgar, 2010). If subcultures assigned to the same morphotype yielded different OTUs, we split the subcultures into separate morphotypes and the new morphotypes were subsequently sequenced to confirm inclusion in an OTU. Representative sequences for each OTU was generated in USEARCH and the taxonomy for each predicted using the "sintax" command (Edgar, 2016) with the Utax (v7.2) sequence dataset (UNITE Community, 2017). In addition, we used the BLAST algorithm (Altschul et al., 1990) against the GenBank database with an e value of $<1 \mathrm{e}-09$ and a coverage of at least $80 \%$ to obtain more detailed taxonomy for each isolate that was sequenced. Sequences are hosted in GenBank under accession numbers MT820041:MT820113.

\subsection{Statistical analysis}

\subsubsection{Are there altitudinal gradients in the composition or diversity} of culturable root fungi?

To evaluate sensitivity of fungal diversity, the number of isolates cultured (abundance), and fungal OTU composition to altitude, we used elevation (high/low) and focal species identity or plant genus (Table 1, nine species, five genera) as fixed effects, with the random effect of replicate watershed (Table 2, three watersheds) in general linear mixed effects models. To assess the number of culturable isolates, we counted and tracked all isolates on each plate. Fungal isolates were characterized into morphotypes by visual assessment, followed by Sanger sequencing of similar morphotypes. For fungal community composition, we used a Bray-Curtis distance matrix to conduct permutational MANOVA in Primer version 6 (Clarke and Gorley, 2009). Pseudo- $F$ statistics were calculated with Type III sums of squares. We visualized community composition using nonmetric multidimensional scaling (NMDS) analysis with 500 re-starts (3-dimensional stress $=0.12$ following the exclusion of one outlier sample that had low fungal abundance (P. leptocoma at East River 
low). Analysis of multivariate dispersion (permDISP, 9999 permutations, Primer v. 6, Clarke and Gorley, 2009) showed no significant heterogeneity in dispersion by elevation or by plant species (Table 3a).

To assess fungal diversity responses, we calculated the Shannon diversity index, OTU richness, and the inverse Simpson Evenness index in the <vegan> package (Oksanen et al., 2018) in R (R Core Team, 2018) from an OTU matrix in which samples were rows, OTUs were columns, and each cell was the number of times we isolated each OTU from the root sample. For diversity metrics, we built mixed effect models using $<$ lmer $>$ in the lme4 (v1.1-19) package (Bates et al., 2015) with the fixed effects of elevation $\mathrm{x}$ genus, as well as plant species nested within genus and watershed as a random effect. Models were evaluated using analysis of deviance with function $<$ Anova $>$ in the car package (Fox and Weisberg, 2019). For significant main effects, posthoc comparisons and 95\% confidence intervals were obtained using the emmeans package (Lenth, 2018) with a false discovery rate correction for multiple comparisons.

\subsubsection{Do culturable root fungi respond to experimental warming?}

We applied a similar analysis framework to the warming experiment. Models for fungal diversity metrics were built with $<$ lmer $>$ with the fixed effects of the warming treatment (warmed/control) and plant species identity (Table 1, three species), warming x plant species, and the random effect of block (spatially paired warm/ control plots). Fungal OTU composition was analyzed with the same model structure implemented in perMANOVA (Clarke and Gorley, 2009). Analysis of multivariate dispersion (permDISP, 9999 permutations, Primer v. 6) showed no significant heterogeneity in dispersion by treatment or plant species (Table $3 \mathrm{~b}$ ), indicating similar degrees of turnover in OTUs among individual samples within a treatment or plant species group.

\subsubsection{Are fungal responses to direct warming predictable based on their altitudinal distributions?}

A significantly positive correlation between a species decline with low elevation and its decline under experimental warming would indicate that fungal responses to warming were predictable from their altitudinal distributions. A subset of 11 fungal taxa co-occurred in a sufficient number of sites and plots (at least 3 of each per study) to compare their sensitivities to both elevation and experimental warming (see Results: Fungal composition, Fig. 1). We determined a measure of effect size for each OTU using the Relative Interaction Intensity metric (RII) (Armas et al., 2004) because it scales symmetrically from -1 to 1 . We calculated RII for the altitudinal survey as: (mean abundance at low elevation - mean abundance at high elevation)/(mean abundance at low elevation + mean abundance at high elevation). Thus, OTUs that were most abundant at low elevation had a positive RII, and taxa that were most abundant at high elevation had negative RII. For the warming meadow experiment, $R I I=$ (mean abundance in warmed plots - mean abundance in control plots)/(mean abundance in warmed plots + mean abundance in control plots). Thus, fungal taxa that increased with warming had a positive RII and those that declined with warming had a negative RII. We then used Pearson product-moment correlation to evaluate whether responsiveness to warming was predictable from the change in abundance with elevation, using each OTU as an observation. Both variables were normally distributed.

\section{Results}

\subsection{Fungal composition}

We cultured 1517 fungal isolates from the altitudinal survey and the warming experiment combined. We sequenced 606 of these isolates, which were clustered to 77 OTUs (Supporting Material, Table S1). Ascomycetes were the most common phylum of fungi, comprising $84 \%$ of the OTUs (Supporting Material, Table S1). Basidiomycota comprised $12 \%$ of OTUs and Mortierellomycota were $4 \%$. Common orders were Pleosporales (30\% of OTUs), Helotiales (23\%), and Hypocreales (13\%) (Table S1).

The five most abundant OTUs were consistent across both the altitudinal survey and the warming experiment. OTU1 Fusarium tricinctum (Ascomycota: Hypocreales) comprised 18\% of isolates for altitudinal samples and $27 \%$ in the warming experiment and is considered to be a weak plant pathogen with a broad host range and geographical distribution (Norberg et al., 2014). Unidentified taxa were common: OTU23 (an unidentified Helotiales) comprised $15 \%$ of isolates for altitudinal samples and $12 \%$ for the warming experiment, OTU12 (an unidentified Pleosporales) comprised $11 \%$ of isolates for altitudinal samples and $8 \%$ in the warming experiment, and OTU45 (another Helotiales) was $6 \%$ of isolates in the altitude study and $9 \%$ in the warming experiment. A Mycena sp. (OTU34, Basidiomycota: Agaricales: Mycenaceae) was the fifth most abundant taxon in the survey and fourth in the warming experiment, comprising $4 \%$ and $10 \%$ of isolates, respectively. Mycena form small saprotrophic mushrooms that are typically gray or brown (Smith, 1947), and have been previously characterized from grass roots and litter (Geesteranus, 1991; Osono, 2010; Tejesvi et al., 2013). An Ophiosphaerella sp. (Ascomycota: Pleosporales: Phaeosphaeriaceae) - a genus containing common turfgrass pathogens - was $4 \%$ of altitudinal survey isolates, and a Plectania sp. (Ascomycota: Pezizales: Sarcosomataceae), commonly associated with melting snow, was $4 \%$ of isolates in the altitudinal survey and $3 \%$ of isolates in the warming experiment.

Spatial variation in fungal composition among watersheds was larger than variation associated with altitude. Of the 54 taxa collected from the large spatial scale of the altitudinal survey $(\sim 10 \mathrm{~km}), \sim 30 \%(17 / 54)$ were shared between the high and low elevation sites (Fig. 1A) and just 15\% (8/54) were present in all three watersheds (Fig. 1B). At the small spatial scale of the warming experiment $(40 \mathrm{~m} \times 100 \mathrm{~m}), \sim 40 \%(23 / 54)$ of the taxa cultured were present in both warmed and control plots (Fig. 1C). In addition, within each study, plant species shared some taxa but also had many unique fungal OTUs (Fig. 1D\&E). In the altitudinal study, just seven percent $(4 / 54)$ of taxa were shared among all six grasses surveyed whereas $17 \%(9 / 54)$ of taxa were shared among the three grass species sampled in the small footprint of the warming experiment.

Both altitude (Fig. 2) and experimental warming (Fig. 3) had marginally non-significant effects on the community composition of culturable root endophytes (Table 3, $0.05<P<0.1$ ). Across the altitudinal survey, plant species identity did not strongly structure fungal composition $(P>0.4)$, but spatial patterns were evident from the significant effect of watershed identity (Table 3a), indicating sufficient statistical power for this dataset. At the small spatial scale of the warming experiment, warming had a weaker effect on fungal composition than the identity of plant species (Fig. 3); the three grass species significantly diverged in fungal composition (Table $3 \mathrm{~b}$, $P<0.03$ ). Neither warming nor elevation altered the dispersion of fungal communities among samples (Table 3).

\subsection{Fungal diversity}

Overall, OTU fungal abundance and diversity did not significantly vary with elevation (Table 4a, "Altitudinal Gradient") and did not decline under experimental warming (Table 4b, "Treatment"). However, altitudinal gradients in diversity indices were detected for some grass species, and these patterns diverged based on plant identity (Fig. 4, Table 4a, "Altitudinal Gradient X Genus"). Specifically, Poa species had $25-60 \%$ greater fungal isolate abundance (Fig. 4A, Elevation, $X^{2}=16.7, P<0.0001$ ) and $25-38 \%$ greater fungal 
A

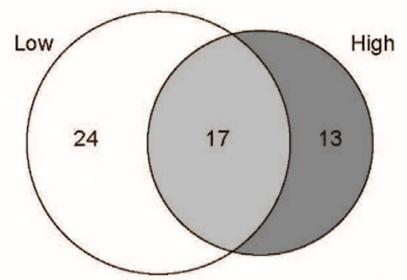

D

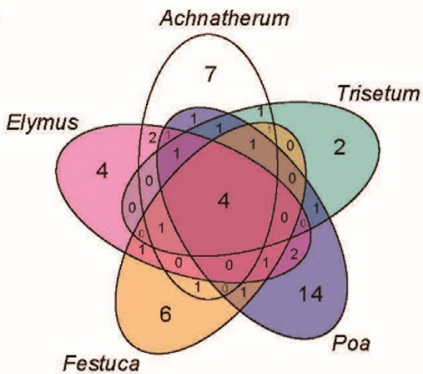

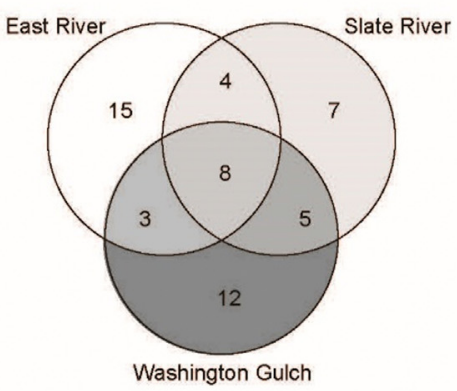

C

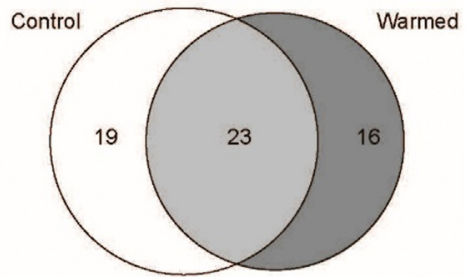

$\mathrm{E}$

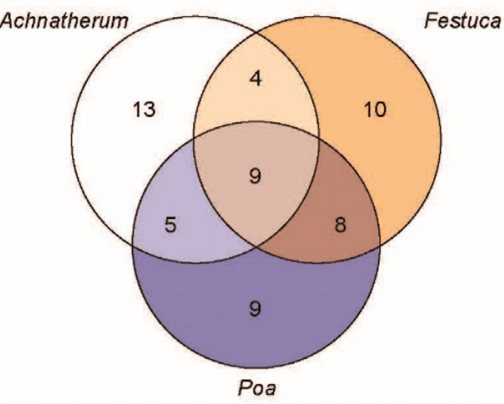

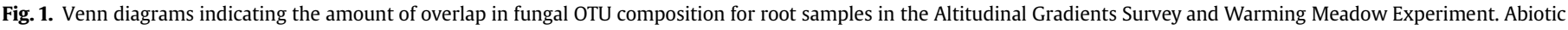

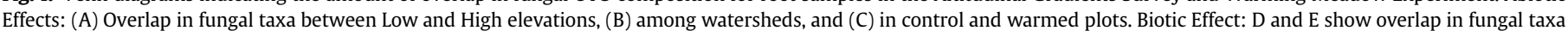

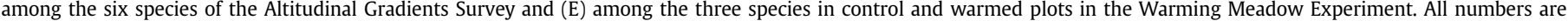
numbers of OTUs.

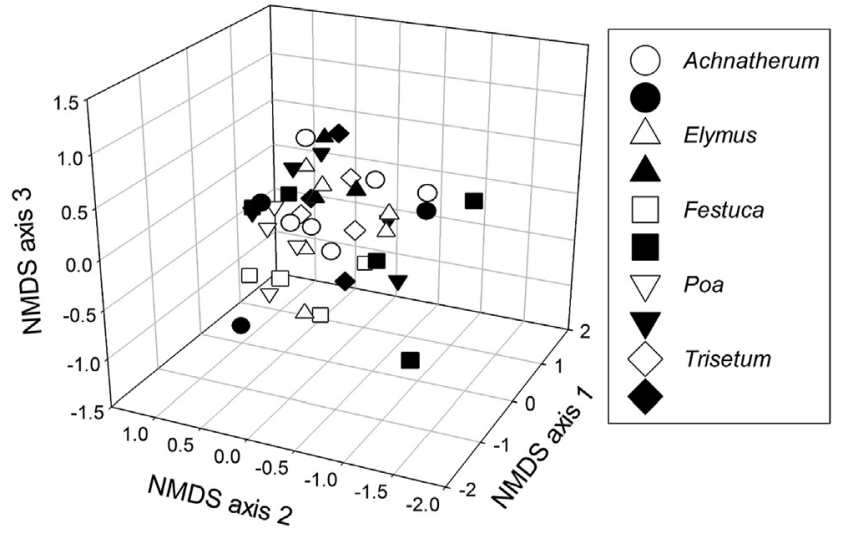

Fig. 2. Nonmetric multidimensional scaling plots depicting variation in fungal community composition for Altitudinal Gradients Survey. Each point is a unique root sample as described in the methods. Open symbols are low elevation sites. Filled symbols are high elevation sites. 3D stress $=0.12$. Elevation: $P=0.0867$ (Table 3a). Genus and species were $n$. $s$.

diversity (Fig. 4B, $X^{2}=27.5, P<0.0001$ ) at high elevation than low elevation sites. The diversity increase for Poa was driven by a combination of $\sim 1.67$ more OTUs per sample for both Poa species (richness $X^{2}=27.5, P<0.0001$ ) and $15-48 \%$ greater evenness (Elevation, $X^{2}=19.2, P<0.0001 ;$ Fig. 4). In contrast, F. thurberi had $64 \%$ lower fungal diversity on roots at high elevation (Fig. 4B, Elevation, $\left.X^{2}=14.7, P=0.0001\right)$, driven by 2.3 fewer OTUs $\left(X^{2}=9.6\right.$, $P=0.0020)$ and $70 \%$ lower evenness $\left(X^{2}=19.4, P<0.0001\right)$. No other plant taxon had significant altitudinal patterns in fungal diversity or abundance (Fig. 4).

Plant species also trended toward divergence in fungal diversity and evenness on the small spatial scale of the warming meadow experiment $(<10 \%$ probability that data support the null hypothesis of difference: Table 4b, Plant Species, $0.05<P<0.1$ ). Poa pratensis had the highest fungal diversity and evenness in roots (Shannon
$H^{\prime}=0.98 \pm 0.10$, Inverse Simpson $1 / D=2.64 \pm 0.23$ ) relative to either A. lettermanii $\left(H^{\prime}=0.77 \pm 0.10,1 / D=2.20 \pm 0.22\right)$ or F. thurberi $\left(H^{\prime}=0.79 \pm 0.10,1 / D=2.19 \pm 0.22\right.$ ) (Table $\left.4 \mathrm{~b}\right)$.

\subsection{Individual fungal taxa}

The response of individual fungal taxa to experimental warming was positively correlated with their altitudinal distributions (Fig. 5, Pearson $r=0.61, P=0.046$ ). Specifically, fungal taxa that were most abundant in warmed plots were also most abundant at lower elevations. The two taxa that were more abundant at high elevations also declined under warming. Clonostachys rosea (Bionectriaceae, Hypocreales, OTU26) was absent from warmed plots and present only in $F$. thurberi. OTU23 (unidentified Helotiales) declined with elevation and under warming $(R I I=-0.31)$ and was a generalist present in all three warming meadow grass species (Supporting Information, Table S1). Generally, those fungi that were more abundant at low elevation had positive or neutral responses to experimental warming. The strongest increases under warming were two taxa present in all three plant species: OTU3 - Cadophora sp. (Helotiales, RII warming $=0.76$ ) and OTU6 - Lachnum sp. (Hyaloscyphaceae, Helotiales, RII warming $=0.48$ ). In addition, one fungus that was absent from $F$. thurberi (OTU5 - Fusarium redolens (Nectriaceae, Hypocreales)) had strong positive response to warming ( $R I I=+0.27$ ) across the other two grass species (Table S1).

\section{Discussion}

4.1. Are there altitudinal gradients in the composition or diversity of culturable root fungi?

The majority (68\%) of root endophytes varied with elevation but caused relatively small shifts in overall fungal composition between high and low elevation sites. This pattern was not driven by changes in 
(A) Achnatherum lettermanii

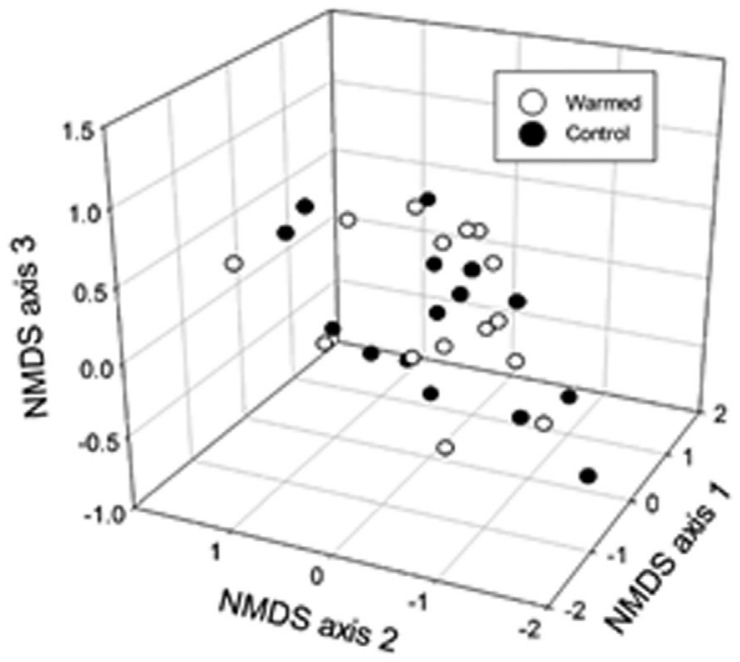

(B) Festuca thurberi

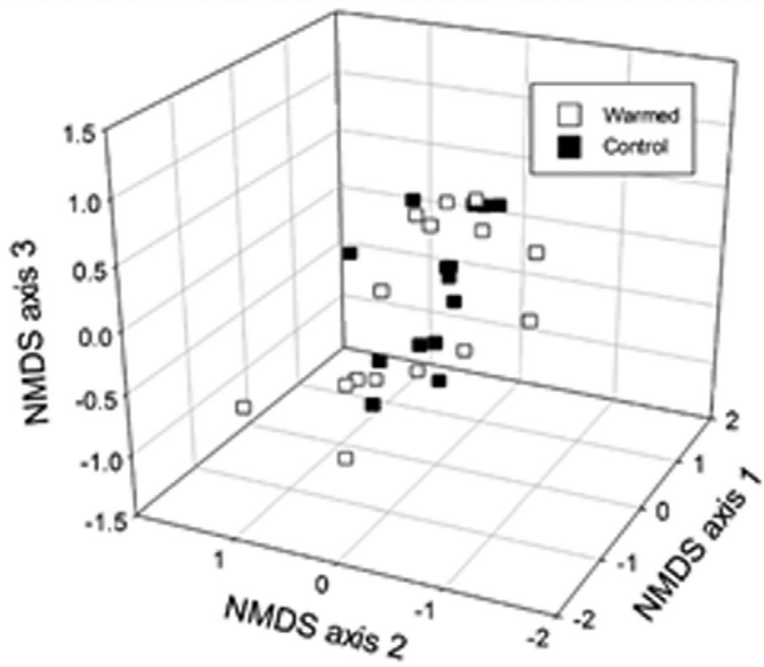

(C) Poa pratensis

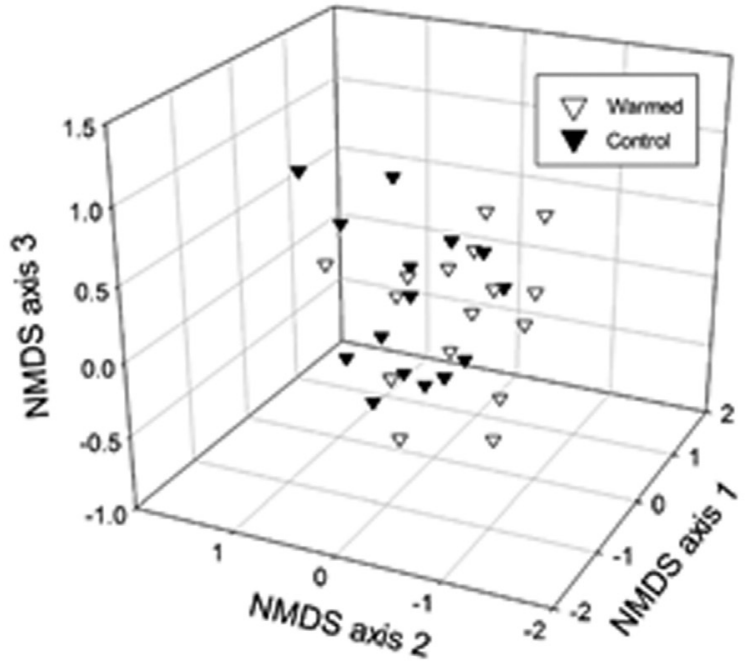

Fig. 3. Nonmetric multidimensional scaling plots depicting variation in fungal community composition in the Warming Meadow Experiment for (A) Achnatherum lettermanii, (B) Festuca thurberi, or (C) Poa pratensis. Each point is a unique root sample from an individual plant. Open symbols are warmed plots. Filled symbols are control plots. 3D stress for the ordination (all species together) $=0.13$. Plant species identity $(P=0.0062)$ had a stronger influence than warming $(P=0.0955$, Table $3 \mathrm{~b})$.

root endophyte diversity (gains or losses of species), but instead by individual root endophyte taxa that appear to be sorted by the steep altitudinal gradients as well as by plant host identity. Importantly, plant species identity shaped the relationships between fungal endophyte communities and altitude, even though there was not a strong overall signature of plant species identity on root endophyte composition. Specifically, root endophyte abundance and diversity peaked at high elevation sites in Poa spp. but peaked at low elevations in $F$. thurberi. In previous culture-based and next-generation sequencing surveys of the same plant species, their leaf fungal endophytes similarly showed host-specific altitudinal trends in diversity and abundance (Kazenel et al., 2019, Kivlin et al., 2019). Additionally, the abundance of AMF colonizing roots displayed species-specific trends with elevation in an earlier study (Ranelli et al., 2015).

Several interacting mechanisms may explain the variation in fungal diversity and composition among plant species over environmental gradients. For example, these trends may reflect differential plant host filtering for fungal symbionts throughout portions of their altitudinal range that vary in conspecific host densities (Cobian et al., 2019). Plants may select fungi based on their contextdependent costs and benefits under different abiotic environments (Afkhami et al., 2014). Alternatively, environmental selection for suitable abiotic and biotic conditions may structure plant-fungal symbiont communities along multivariate resource gradients (Kivlin et al., 2017). Additional manipulative studies that study more than one plant host, such as ours with temperature, could help disentangle these potential interactive effects.

\subsection{Do culturable root fungi respond to experimental warming?}

Individual root fungal endophytes responded to $27 \mathrm{y}$ of experimental warming. For example, OTU26 - Clonostachys rosea and OTU23 only occurred in control plots whereas OTU3, OTU5, and OTU6 were mostly found in warmed plots. These effects were fungal-taxon specific and did not translate into broader patterns of shifts in fungal diversity or composition with warming. Previous results from nextgeneration sequencing of these plots confirm this trend: The overall abundance, diversity, and composition of root fungal endophyte did not vary with warming (Kazenel et al., 2019). In other warming experiments, species-specific response of root fungal endophytes have been common (Fujimura et al. 2008), and sensitivities may vary among fungal functional guilds, with increases in dark septate endophytes and decreases in other fungal endophytes in warmed versus cool environments (Olsrud et al., 2010). Aboveground, foliar fungal symbionts also had idiosyncratic responses to warming in our host species. Leaf fungal endophyte abundance was only sensitive to warming in one plant host (Festuca thurberi), and neither culturebased nor next-generation sequencing revealed significant effects of the warming treatment on foliar fungal endophyte diversity or composition (Kazenel et al., 2019; Kivlin and Rudgers, 2019). Instead, individual fungal endophytes may shift their metabolism to betteracclimate to warmer conditions (Kivlin and Rudgers, 2019); unfortunately, such plasticity in fungal responses to climate is not yet predictable given the limited data available. 
Table 3

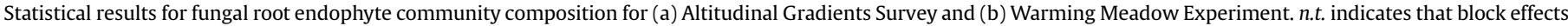
on community dispersion were not tested. $P$-values $<0.05$ shown in bold and $P<0.10$ in italics.

\begin{tabular}{|c|c|c|c|c|c|c|}
\hline \multirow[b]{2}{*}{ (a) } & \multicolumn{3}{|c|}{ PERMANOVA } & \multicolumn{3}{|c|}{ PERMDISP } \\
\hline & pseudo- $F$ & $d f$ & $P$ & $F$ & $d f$ & $P$ \\
\hline Altidudinal Gradient & 1.57 & 1 & 0.0867 & 0.64 & 1,42 & 0.5642 \\
\hline Watershed & 1.59 & 2 & 0.0284 & 1.23 & 2,41 & 0.3526 \\
\hline $\begin{array}{l}\text { Plant species } \\
\text { (b) }\end{array}$ & 1.01 & 8 & 0.4498 & 1.23 & 2,35 & 0.6413 \\
\hline Treatment & 1.60 & 1 & 0.0955 & 0.06 & 1,89 & 0.819 \\
\hline Plant species & 1.98 & 2 & 0.0062 & 1.06 & 2,88 & 0.4169 \\
\hline Plant species X Treatment & 0.83 & 2 & 0.6834 & 1.03 & 5,85 & 0.3773 \\
\hline Block & 2.05 & 4 & 0.0004 & n.t. & n.t. & n.t. \\
\hline
\end{tabular}

Table 4

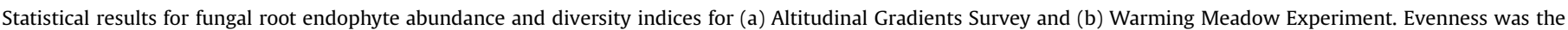
inverse Simpson index. $P$-values $<0.05$ shown in bold and $P<0.10$ in italics.

\begin{tabular}{|c|c|c|c|c|c|c|c|c|}
\hline \multirow[b]{2}{*}{ (a) } & \multicolumn{2}{|c|}{ Isolate abundance } & \multicolumn{2}{|c|}{ Shannon $H^{\prime}(\log )$} & \multicolumn{2}{|c|}{ Species richness } & \multicolumn{2}{|c|}{ Evenness (log) } \\
\hline & $X^{2}$ & $P$ & $X^{2}$ & $P$ & $X^{2}$ & $P$ & $X^{2}$ & $P$ \\
\hline Altitudinal Gradient & 0.65 & 0.4195 & 0.8 & 0.3702 & 0.39 & 0.53 & 1.86 & 0.1731 \\
\hline Genus & 1.75 & 0.7822 & 8.81 & 0.0659 & 5.49 & 0.2492 & 5.37 & 0.2511 \\
\hline Altidudinal Gradient X Genus & 8.12 & 0.0874 & 12.65 & 0.0131 & 11.11 & 0.0254 & 13.21 & 0.0103 \\
\hline $\begin{array}{l}\text { Plant species (Genus) } \\
\text { (b) }\end{array}$ & 5.5 & 0.2398 & 1.75 & 0.7809 & 3.24 & 0.5192 & 5.05 & 0.282 \\
\hline Treatment & 0.24 & 0.6221 & 0.12 & 0.7318 & 0.02 & 0.8903 & 0.04 & 0.8503 \\
\hline Plant species & 0.21 & 0.9002 & 5.08 & 0.0787 & 2.67 & 0.2632 & 5.41 & 0.0669 \\
\hline Plant species X Treatment & 0.71 & 0.7015 & 1.5 & 0.4723 & 1.03 & 0.5966 & 2.11 & 0.3479 \\
\hline
\end{tabular}
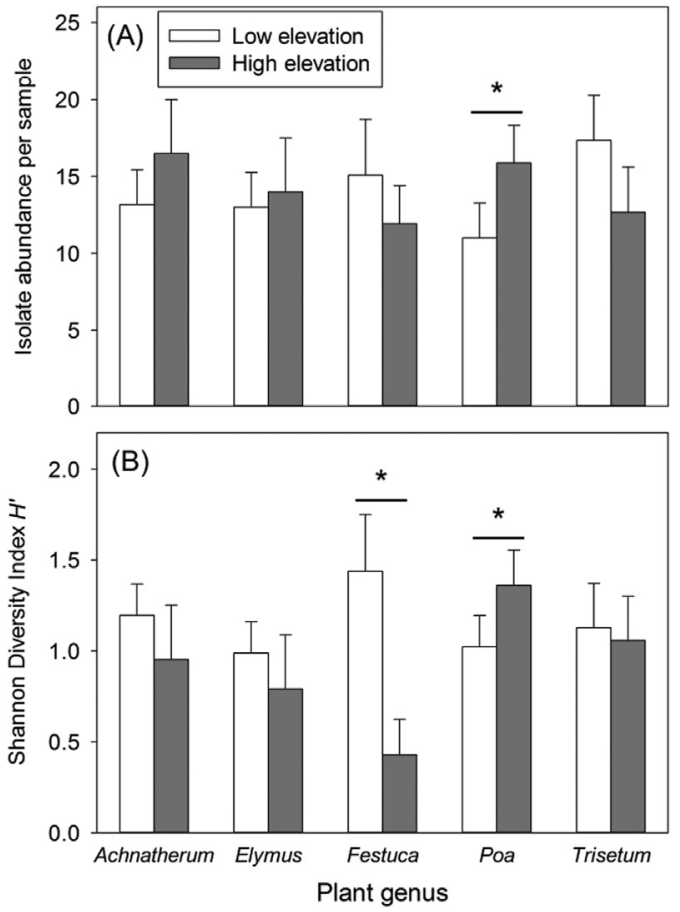

Fig. 4. Altitudinal Gradients Survey means \pm s. e. from linear mixed effects models evaluating the influence of elevation (low or high) on (A) culturable root fungal abundance or (B) fungal diversity (Shannon index, $H^{\prime}$ ). Asterisks indicate pairwise comparisons within a genus with $P<0.05$.

\subsection{Are fungal responses to direct warming predictable from their} altitudinal distributions?

For common root fungal endophytes, altitudinal distributions could provide inference into their sensitivity to warming: Fungal taxa that declined with warming were also less abundant at lower than higher elevation sites across the altitudinal survey. This is one of the first indications that space-for-time substitution can partially inform fungal root endophyte responses to warming. However, this effect was not predictable based on limited data available for fungal evolutionary histories, life-history strategies (e.g., decomposer versus pathogen), or growth form. Specifically, the four main responders to warmer climates were Clonostachys rosea (Hypocreales), Cadophora sp. (Helotiales), Lachnum sp. (Helotiales) and Fusarium redolens (Hypocreales). While all of these species are within phylum Ascomycota, the taxa come from two distinct subphyla (Pezizomycetes and Sordariomycetes). Furthermore, whereas some of these taxa are usually beneficial to plant hosts, protecting plants from pathogens (e.g., Clonostachys rosea), others can be pathogenic (e.g., Cadophora, Fusarium redolens), or have wide distributions on a variety of substrates (e.g., Lachnum). The specific ecological roles of these species in association with host plants in our study remain unknown. Thus, a predictive framework for fungal symbiont winners and losers with climate change is still elusive.

Determining the ecological outcomes of specific plant-fungal symbioses will be critical if plant success in new environments depends on interactions with fungal symbionts (Kivlin et al., 2013; Ramirez et al., 2019). For example, plant altitudinal shifts with climate change may be hindered via establishment lags if certain 


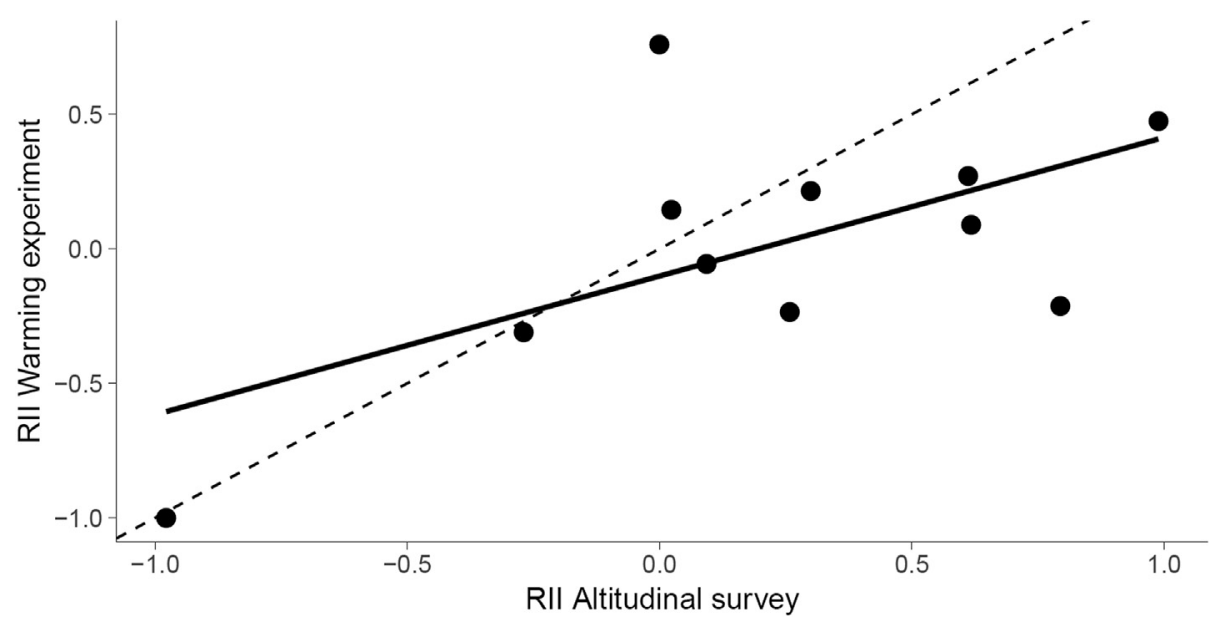

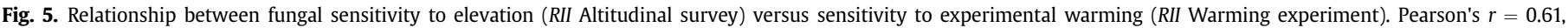
$P=0.046$, slope estimate $\beta=0.52 \pm 0.22$. The dashed line shows the $1: 1$.

biotic interactions are absent from the novel species range (Alexander et al., 2018). Similarly, reciprocal transplants of plants and their fungal symbionts along altitudinal gradients have shown a home field advantage, where plants grow largest with symbionts that originate from their local elevation. However, the outcomes of specific plant-fungal symbioses are also commonly dependent on the degree of environmental stress (Wagg et al., 2011; Yang et al., 2018). In range-shifting plant species, the successional development of specific plant-fungal interactions common to the home range may require several generations of plant-soil feedback to rebuild (Chung et al., 2018; Collins et al., 2018; Van Nuland et al., 2019). Mismatches between plants and their microbial communities could slow rates of upward plant range expansion in mountain ecosystems and increase the likelihood of plant local extirpation or wholesale extinction under climate change.

\section{Conclusion}

Root-associated fungi, like their host plants (Smith et al., 2009), likely follow a hierarchy of responses to altitudinal gradients, natural warming, and global environmental change (Bardgett et al., 2013). Results of this study must be analyzed with caution as samples were collected over a 2 week period at the beginning of the growing season and fungal isolates were grown on a single culture medium for all plant species across all treatments. Nonetheless, several trends emerge. First, individual organisms can respond through changes in physiology, morphology, growth or reproduction. Our culture-based study revealed both winner and loser fungal taxa under long-term experimental warming, providing evidence of this first-level response. Second, global change can cause community reordering, altering whole community composition and the rank abundances of species. We found only weak support for re-ordering, with marginally non-significant changes in the fungal composition of plant roots subjected to long-term warming. The influence of abiotic conditions was generally weaker than that of host plant species identity, suggesting that non-mycorrhizal root endophytes may be relatively resilient to climate warming. This may be good news where hostsymbiont associations benefit the fitness of native grass species. Third, species loss and immigration can cause the largest ecological responses to global change. Experimental manipulations may lack power to detect such responses because taxa can disperse across the small spatial scales of experimental plots. Our study detected just one species (Clonostachys rosea) that was present in control plots but absent under warming. However, general concordance between the altitudinal distributions of fungal OTUs and the magnitude of their responses to warming provides some optimism that geographic patterns in fungal abundances can help to predict their future sensitivities to warming (but see Kazenel et al., 2019). Importantly, our work supports other recent studies (Becklin et al., 2012; Li et al., 2014; Davison et al., 2016; Pôlme et al., 2018; Cobian et al., 2019; Rudgers et al., n.d.) documenting strong plant-species specificity in the biogeography of plant-associated fungi, indicating that studies of single plant taxa will not reveal general patterns for Ascomycota and other non-mycorrhizal endophytes in plant roots.

\section{Acknowledgements}

This work was supported by NSF DEB\#t1354972 awarded to JAR, DLT, and SNK as well as a supplemental ROA to KGL on NSF DEB\#1456955 to JAR.

\section{Appendix A. Supplementary data}

Supplementary data to this article can be found online at https://doi.org/10.1016/j.funeco.2020.101002.

\section{References}

Afkhami, M.E., Rudgers, J.A., Stachowicz, J.J., 2014. Multiple mutualist effects: conflict and synergy in multispecies mutualisms. Ecology 95, 833-844.

Alexander, J.M., Chalmandrier, L., Lenoir, J., Burgess, T.I., Essl, F., Haider, S., Kueffer, C., McDougall, K., Milbau, A., Nunez, M.A., Pauchard, A., Rabitsch, W., Rew, L.J., Sanders, N.J., Pellissier, L., 2018. Lags in the response of mountain plant communities to climate change. Global Change Biol. 24, 563-579. https://doi.org/ $10.1111 /$ gcb.13976.

Altschul, S.F., Gish, W., Miller, W., Myers, E.W., Lipman, D.J., 1990. Basic local alignment search tool. J. Mol. Biol. 215, 403-410. https://doi.org/10.1016/S00222836(05)80360-2.

Armas, C., Ordiales, R., Pugnaire, F.I., 2004. Measuring plant interactions: a new comparative index. Ecology 85, 2682-2686. https://doi.org/10.1890/03-0650.

Averill, C., Bhatnagar, J.M.T., Dietz, M., Pearse, W.D., Kivlin, S.N., 2019. Global imprint of plant mycorrhizal associations on plant nutrient use efficiency traits. Proc. Natl. Acad. Sci. Unit. States Am. 116, 23163-23168.

Bardgett, R.D., Manning, P., Morrien, E., De Vries, F.T., 2013. Hierarchical responses of plant-soil interactions to climate change: consequences for the global carbon cycle. J. Ecol. 101, 334-343. https://doi.org/10.1111/1365-2745.12043.

Bates, D., Maechler, M., Bolker, B., Walker, S., 2015. Fitting linear mixed-effects models using lme4. J. Stat. Software 67, 1-48. https://doi.org/10.18637/ jss.v067.i01.

Becklin, K.M., Hertweck, K.L., Jumpponen, A., 2012. Host identity impacts rhizosphere fungal communities associated with three alpine plant species. Microb. Ecol. 63, 682-693. https://doi.org/10.1007/s00248-011-9968-7.

Bowman, W.D., Hacker, S.D., Cain, M.L., 2017. Ecology, Fourth. Sinauer Associates Oxford University Press. 
Chen, I.-C., Hill, J.K., Ohlemüller, R., Roy, D.B., Thomas, C.D., 2011. Rapid range shifts of species associated with high levels of climate warming. Science 333, 1024. https://doi.org/10.1126/science.1206432.

Chung, Y.A., Jumpponen, A., Rudgers, J.A., 2018. Divergence in diversity and composition of root-associated fungi between greenhouse and field studies in a semiarid grassland. Microbial Ecology in press.

Clarke, K.R., Gorley, R.N., 2009. Primer Version 6.1.10 User Manual and Tutorial. Primer-E, Plymouth.

Cobian, G.M., Egan, C.P., Amend, A.S., 2019. Plant-microbe specificity varies as a function of elevation. ISME J. 13, 2778-2788. https://doi.org/10.1038/s41396019-0470-4.

Collins, C.G., Stajich, J.E., Weber, S.E., Pombubpa, N., Diez, J.M., 2018. Shrub range expansion alters diversity and distribution of soil fungal communities across an alpine elevation gradient. Mol. Ecol. 27, 2461-2476. https://doi.org/10.1111/ mec.14694.

Community, U.N.I.T.E., 2017. UNITE USEARCH/UTAX Release. https://doi.org/ 10.15156/BIO/587476.

Davison, J., Moora, M., Jairus, T., Vasar, M., Opik, M., Zobel, M., 2016. Hierarchical assembly rules in arbuscular mycorrhizal (AM) fungal communities. Soil Biol. Biochem. 97, 63-70. https://doi.org/10.1016/j.soilbio.2016.03.003.

De Valpine, P., Harte, J., 2001. Plant responses to experimental warming in a montane meadow. Ecology 82, 637-648. https://doi.org/10.1890/0012-9658(2001)082 [0637:prtewi]2.0.co;2.

Diamond, S.E., Nichols, L.M., McCoy, N., Hirsch, C., Pelini, S.L., Sanders, N.J., Ellison, A.M., Gotelli, N.J., Dunn, R.R., 2012. A physiological trait-based approach to predicting the responses of species to experimental climate warming. Ecology 93, 2305-2312. https://doi.org/10.1890/11-2296.1.

Edgar, R.C., 2010. Search and clustering orders of magnitude faster than BLAST. Bioinformatics 26, 2460-2461. https://doi.org/10.1093/bioinformatics/btq461.

Edgar, R.C., 2016. SINTAX: a simple non-Bayesian taxonomy classifier for $16 \mathrm{~S}$ and ITS sequences. bioRxiv, 074161. https://doi.org/10.1101/074161.

Engler, R., Randin, C.F., Thuiller, W., Dullinger, S., Zimmermann, N.E., AraÚJo, M.B., Pearman, P.B., Le Lay, G., Piedallu, C., Albert, CécH., Choler, P., Coldea, G., De Lamo, X., DirnbÖCk, T., GÉGout, J.-C., GÓMez-GarcÍA, D., Grytnes, J.-A., Heegaard, E., HØIstad, F., NoguÉS-Bravo, D., Normand, S., PuŞCaŞ, M., SebastiÀ, M.-T., Stanisci, A., Theurillat, J.-P., Trivedi, M.R., Vittoz, P., Guisan, A., 2011. 21st century climate change threatens mountain flora unequally across Europe. Global Change Biol. 17, 2330-2341. https://doi.org/10.1111/j.13652486.2010.02393.x.

Fox, J., Weisberg, S., 2019. An $\{R\}$ Companion to Applied Regression, third ed. Sage, Thousand Oaks CA.

Fujimura, K., Egger, K., Henry, G., 2008. The effect of experimental warming on the root-associated fungal community of Salix arctica. ISME J. 2, 105-114. https:// doi.org/10.1038/ismej.2007.89.

Gai, J.P., Tian, H., Yang, F.Y., Christie, P., Li, X.L., Klironomos, J.N., 2012. Arbuscular mycorrhizal fungal diversity along a Tibetan elevation gradient. Pedobiologia 55, 145-151. https://doi.org/10.1016/j.pedobi.2011.12.004.

Gardes, M. Dahlberg, A., 1996. Mycorrhizal diversity in arctic and alpine tundra: an open question. New Phytol. 133, 147-157.

Geesteranus, R., 1991. Studies in mycenas. Proc. K. Ned. Akad. Wet. Biol. Chem. Geol. Phys. Med. Sci. 94, 377-403.

Geneious, 2018. Geneious 11.1.4. https://www.geneious.com.

Griekspoor, A., Groothuis, T., 2018. 4Peaks nucleobytes.Com.

Harte, J., Shaw, R., 1995. Shifting dominance within a montane vegetation community - results of a climate warming experiment. Science 267, 876-880. https://doi.org/10.1126/science.267.5199.876.

Harte, J., Saleska, S.R., Levy, C., 2015. Convergent ecosystem responses to 23-year ambient and manipulated warming link advancing snowmelt and shrub encroachment to transient and long-term climate-soil carbon feedback. Global Change Biol. 21, 2349-2356. https://doi.org/10.1111/gcb.12831.

Haselwandter, K., Read, D.J., 1980. Fungal associations of roots of dominant and subdominant plants in high alpine vegetation systems with special reference to mycorrhiza. Oecologia 45, 57-62. https://doi.org/10.1007/bf00346707.

IPCC, 2014. In: Pachauri, R.K., Meyer, L.A. (Eds.), Climate Change 2014: Synthesis Report. Contribution of Working Groups I, II, and III to the Fifth Assessment Report of the Intergovernmental Panel on Climate Change [Core Writing Team. IPCC, Geneva, Switzerland, p. 151 pp.

Katoh, K., Standley, D.M., 2013. MAFFT multiple sequence alignment software version 7: improvements in performance and usability. Mol. Biol. Evol. 30, 772-780. https://doi.org/10.1093/molbev/mst010.

Kazenel, M.R., Kivlin, S.N., Taylor, D.L., Lynn, J.S., Rudgers, J.A., 2019. Altitudinal gradients fail to predict fungal symbiont responses to warming. Ecology 100. https://doi.org/10.1002/ecy.2740, 8th ed.

Kivlin, S.N., Emery, S.M., Rudgers, J.A., 2013. Fungal symbionts alter plant responses to global change. Am. J. Bot. 100, 1445-1457.

Kivlin, S.N., Kazelen, M.R., Lynn, J.S., Taylor, D.L., Rudgers, J.A., 2019. Plant identity influences foliar endophytes more than elevation in the Colorado Rocky Mountains. Microbial Ecology 78, 688-698. https://doi.org/10.1007/s00248019-01336-4.

Kivlin, S.N., Lynn, J.S., Kazenel, M.R., Beals, K.K., Rudgers, J.A., 2017. Biogeography of plant-associated fungal symbionts in mountain ecosystems: a meta-analysis. Divers. Distrib. 23, 1067-1077. https://doi.org/10.1111/ddi.12595.

Kivlin, S.N., Rudgers, J.A., 2019. Effects of warming on fungal leaf endophytes: impacts on physiology, species richness, and composition. In: Mohan, J. (Ed.), Ecosystem Consequences of Soil Warming. Elsevier, pp. 125-140.
Knapp, A.K., Carroll, C.J.W., Griffin-Nolan, R.J., Slette, I.J., Chaves, F.A., Baur, L.E., Felton, A.J., Gray, J.E., Hoffman, A.M., Lemoine, N.P., Mao, W., Post, A.K., Smith, M.D., 2018. A reality check for climate change experiments: do they reflect the real world? Ecology 99, 2145-2151. https://doi.org/10.1002/ecy.2474.

Lenoir, J., Gegout, J.C., Marquet, P.A., de Ruffray, P., Brisse, H., 2008. A significant upward shift in plant species optimum elevation during the 20th century. Science 320, 1768-1771. https://doi.org/10.1126/science.1156831.

Lenth, R., 2018. Emmeans: estimated marginal means, aka least-squares means. R package version 1.3.0.

Lewis, J.S., Farnsworth, M.L., Burdett, C.L., Theobald, D.M., Gray, M., Miller, R.S., 2017. Biotic and abiotic factors predicting the global distribution and population density of an invasive large mammal. Sci. Rep. 7, 44152.

Li, Xiaoliang, Gai, J., Cai, X., Li, Xiaolin, Christie, P., Zhang, F., Zhang, J., 2014. Molecular diversity of arbuscular mycorrhizal fungi associated with two cooccurring perennial plant species on a Tibetan altitudinal gradient. Mycorrhiza 24, 95-107. https://doi.org/10.1007/s00572-013-0518-7.

Liu, D., Penuelas, J., Ogaya, R., Estiarte, M., Tielboerger, K., Slowik, F., Yang, X., Bilton, M.C., 2018. Species selection under long-term experimental warming and drought explained by climatic distributions. New Phytol. 217, 1494-1506. https://doi.org/10.1111/nph.14925.

Lynn, J.S., Kazenel, M.R., Kivlin, S.N., Rudgers, J.A., 2019. Context-dependent biotic interactions control plant abundance across altitudinal environmental gradients. Ecography in press. https://doi.org/10.1111/ecog.04421.

Maherali, H., 2014. Is there an association between root architecture and mycorrhizal growth response? New Phytol. 204, 192-200. https://doi.org/10.1111/ nph.12927.

Masson-Delmotte, V., Zhai, P., Pörtner, H.-O., Roberts, D., Skea, I., Shukla, P.R., Pirani, A., Moufouma-Okia, W., Péan, C., Pidcock, R., Connors, S. Matthews, J.B.R., Chen, Y., Zhou, X., Gomis, M.I., Lonnoy, E., Maycock, T., Tignor, M., Waterfield, T., 2018. Global Warming of $1.5^{\circ} \mathrm{C}$. An IPCC Special Report on the Impacts of Global Warming of $1.5^{\circ} \mathrm{C}$ above Pre-industrial Levels and Related Global Greenhouse Gas Emission pathways, in the Context of Strengthening the Global Response to the Threat of Climate Change, Sustainable Development, and Efforts to Eradicate Poverty.

Miyamoto, Y., Terashima, Y., Nara, K., 2018. Temperature niche position and breadth of ectomycorrhizal fungi: reduced diversity under warming predicted by a nested community structure. Global Change Biol. 24, 5724-5737. https:// doi.org/10.1111/gcb.14446.

Newsham, K.K., 2011. A meta-analysis of plant responses to dark septate root endophytes. New Phytol. 190, 783-793.

Norberg, H., Cantor, M., Dusheyko, S., Hua, S., Poliakov, A., Shabalov, I., Smirnova, T., Grigoriev, I.V., Dubchak, I., 2014. The genome portal of the department of energy joint genome institute. Nucleic Acids Res. 42, D26-D31.

Oksanen, J., Blanchett, F.G., Friendly, M., Kindt, R., Legendre, P., McGlinn, D. Minchin, P., O'Hara, R.B., Simpson, G., Solymos, P., Stevens, M.H.H., Szoecs, E., Wagner, H., 2018. Vegan: community Ecology package R package.

Olsrud, M., Carlsson, B.A.., Svensson, B.M., Michelsen, A., Melillo, J.M., 2010. Responses of fungal root colonization, plant cover and leaf nutrients to long-term exposure to elevated atmospheric $\mathrm{CO}_{2}$ and warming in a subarctic birch forest understory. Global Change Biol. 16, 1820-1829. https://doi.org/10.1111/j.13652486.2009.02079.x.

Osono, T., 2010. Decomposition of grass leaves by ligninolytic litter-decomposing fungi. Grassl. Sci. 56, 31-36. https://doi.org/10.1111/j.1744-697X.2009.00170.x.

Parmesan, C., 2006. Ecological and evolutionary responses to recent climate change. Annu. Rev. Ecol. Evol. Syst. 37, 637-669.

Põlme, S., Bahram, M., Jacquemyn, H., Kennedy, P., Kohout, P., Moora, M., Oja, J., Öpik, M., Pecoraro, L., Tedersoo, L., 2018. Host preference and network properties in biotrophic plant-fungal associations. New Phytol. 217, 1230-1239. https://doi.org/10.1111/nph.14895.

Porras-Alfaro, A., Bayman, P., 2011. Hidden fungi, emergent properties: endophytes and microbiomes. Annu. Rev. Phytopathol. 49, 291-315.

Price, M.V., Waser, N.M., 2000. Responses of subalpine meadow vegetation to four years of experimental warming. Ecol. Appl. 10, 811-823. https://doi.org/ $10.2307 / 2641047$.

R Core Team, 2018. R: A Language and Environment for Statistical Computing. R Foundation for Statistical Computing, Vienna, Austria.

Ramirez, K.S., Snoek, L.B., Koorem, K., Geisen, S., Bloem, L.J., ten Hooven, F., Kostenko, O., Krigas, N., Manrubia, M., Caković, D., van Raaij, D., Tsiafouli, M.A., Vreš, B., Čelik, T., Weser, C., Wilschut, R.A., van der Putten, W.H., 2019. Rangeexpansion effects on the belowground plant microbiome. Nat. Ecol. Evol. 3, 604-611. https://doi.org/10.1038/s41559-019-0828-z.

Ranelli, L.B., Hendricks, W., Lynn, J.S., Kivlin, S.N., Rudgers, J.A., 2015. Biotic and abiotic predictors of fungal symbiont distributions in grasses of the Colorado Rockies. Diversity and Distributions 21, 962-976. https://doi.org/10.1111/ ddi.12310.

Rangwala, I., Miller, J.R., 2012. Climate change in mountains: a review of elevationdependent warming and its possible causes. Clim. Change 114, 527-547. https://doi.org/10.1007/s10584-012-0419-3.

Read, D.J., Haselwandter, K., 1981. Observations on the mycorrhizal status of some alpine plant communities. New Phytol. 88, 341-352. https://doi.org/10.1111/ j.1469-8137.1981.tb01729.x.

Rudgers, J.A., Fox, S., Porras-Alfaro, A., Herrera, J., Reasin, C., Kent, D., Souza, L., Chung, Y.A., Jumpponen, A., -. Biogeography of root-associated fungi in foundation grasses of North American plains. Ecography - In Review.

Rudgers, J.A., Kivlin, S.N., Whitney, K.D., Price, M.V., Waser, N.M., Harte, J., 2014. 
Responses of high-altitude graminoids and soil fungi to 20 years of experimental warming. Ecology 95, 1918-1928.

Ruotsalainen, A.L., Vare, H., Oksanen, J., Tuomi, J., 2004. Root fungus colonization along an altitudinal gradient in North Norway. Arctic Antarct. Alpine Res. 36, 239-243. https://doi.org/10.1657/1523-0430.

Saleska, S., Shaw, M., Fischer, M., Dunne, J., Shaw, M., Holman, M., Still, C., Harte, J., 2002. Carbon-cycle feedbacks to climate change in montane meadows: results from a warming experiment and a natural climate gradient. Global Biogeochem. Cycles 16, 1055. https://doi.org/10.1029/2001GB001573.

Schmidt, S.K., Sobieniak-Wiseman, L.C., Kageyama, S.A., Halloy, S.R.P., Schadt, C.W., 2008. Mycorrhizal and dark-septate fungi in plant roots above 4270 meters elevation in the Andes and Rocky Mountains. Arctic Antarct. Alpine Res. 40, 576-583. https://doi.org/10.1657/1523-0430(07-068)[schmidt]2.0.co;2.

Smith, A.H., 1947. North American Species of Mycena. Univ. of Michigan Press, Ann Arbor, MI, USA.

Smith, M.D., Knapp, A.K., Collins, S.L., 2009. A framework for assessing ecosystem dynamics in response to chronic resource alterations induced by global change. Ecology 90, 3279-3289. https://doi.org/10.1890/08-1815.1.

Taylor, D.L., Booth, M.G., McFarland, J.W., Herriott, I.C., Lennon, N.J., Nusbaum, C., Marr, T.G., 2008. Increasing ecological inference from high throughput sequencing of fungi in the environment through a tagging approach. Mol. Ecol. Resour. 8, 742-752. https://doi.org/10.1111/j.1755-0998.2008.02094.x.

Tejesvi, M.V., Sauvola, T., Pirttila, A.M., Ruotsalainen, A.L., 2013. Neighboring Deschampsia flexuosa and Trientalis europaea harbor contrasting root fungal endophytic communities. Mycorrhiza 23, 1-10. https://doi.org/10.1007/s00572012-0444-0.

Thuiller, W., Albert, C., Araujo, M.B., Berry, P.M., Cabeza, M., Guisan, A., Hickler, T., Midgely, G.F., Paterson, J., Schurr, F.M., Sykes, M.T., Zimmermann, N.E., 2008. Predicting global change impacts on plant species' distributions: future challenges. Perspect. Plant Ecol. Evol. Systemat. 9, 137-152. https://doi.org/10.1016/ j.ppees.2007.09.004

Urban, M.C., 2019. Projecting biological impacts from climate change like a climate scientist. Wiley Interdiscipl. Rev.-Clim. Change 10, e585. https://doi.org/ $10.1002 /$ wcc.585
Van der Putten, W.H., Macel, M., Visser, M.E., 2010. Predicting species distribution and abundance responses to climate change: why it is essential to include biotic interactions across trophic levels. Phil. Trans. Biol. Sci. 365, 2025-2034. https:// doi.org/10.1098/rstb.2010.0037.

Van Nuland, M.E., Ware, I.M., Bailey, J.K., Schweitzer, J.A., 2019. Ecosystem feedbacks contribute to geographic variation in plant-soil eco-evolutionary dynamics across a fertility gradient. Funct. Ecol. 33, 95-106. https://doi.org/10.1111/13652435.13259.

Wagg, C., Husband, B.C., Green, D.S., Massicotte, H.B., Peterson, R.L., 2011. Soil microbial communities from an elevational cline differ in their effect on conifer seedling growth. Plant Soil 340, 491-504. https://doi.org/10.1007/s11104-0100621-x.

Wang, Q., Fan, X., Wang, M., 2016. Evidence of high-elevation amplification versus Arctic amplification. Sci. Rep. 6, 19219.

White, T.J., Bruns, T., Lee, S., Taylor, J., 1990. Amplification and direct sequencing of fungal ribosomal RNA genes for phylogenetics. In: Innis, M.A., Gelfand, D.H., Sninsky, J.J., White, T.J. (Eds.), PCR Protocols a Guide to Methods and Applications. Academic Press, New York, pp. 315-322.

Wu, B., Hogetsu, T., Isobe, K., Ishii, R., 2007. Community structure of arbuscular mycorrhizal fungi in a primary successional volcanic desert on the southeast slope of Mount Fuji. Mycorrhiza 17, 495-506. https://doi.org/10.1007/s00572007-0114-9.

Yang, R., Li, S., Qin, Z., Cai, X., Li, X., Christie, P., Zhang, J., Feng, G., Gai, J., 2018. Importance of AM fungi and local adaptation in plant response to environmental change: field evidence at contrasting elevations. Fungal Ecol. 34, 59-66. https://doi.org/10.1016/j.funeco.2018.04.006.

Zorio, S.D., Williams, C.F., Aho, K.A., 2016. Sixty-five years of change in montane plant communities in western Colorado. U.S.A. Arctic Antarct. Alpine Res. 48, 703-722. https://doi.org/10.1657/AAAR0016-011.

Zubek, S., Blaszkowski, J., Delimat, A., Turnau, K., 2009. Arbuscular mycorrhizal and dark septate endophyte colonization along altitudinal gradients in the tatra mountains. Arctic Antarct. Alpine Res. 41, 272-279. https://doi.org/10.1657/ 1938-4246-41.2.272. 